\title{
GADIMATH: Gamified Discrete Mathematics
}

\author{
Jan Mark S. Garcia ${ }^{1}$ and Reymund L. Sabay ${ }^{2}$ \\ ${ }^{1}$ West Visayas State University-Himamaylan City Campus, Negros Occidental, Philippines \\ ${ }^{2}$ University of Negros Occidental-Recoletos, Bacolod City, Philippines
}

\section{Article history \\ Submitted: 13 July 2020 \\ Revised: 2 November 2020 \\ Accepted: 16 November 2020}

\section{Keywords}

Information Technology

GADIMATH

Learning Reinforcement

Scaffolding of Activities

Gamification

Two-Dimensional

Interactive Environment

Mind-Setting Goal

Introduction. GADIMATH: Gamified Discrete Mathematics is an interactive two-dimensional mobile-based application in discrete mathematics working on the Android program. This application would work as an additional tool to strengthen the students' training in discrete mathematics. It would benefit students to observe particular rules, accomplish goals, and resolve problems. Upon using the application, students would experience enjoyment, interaction, and motivation while learning takes place. The problems and difficulties that the students encountered towards mastering learning competencies in mathematics are the instructions, school adjustments, and overextended schedules (Ganal \& Guiab, 2014). With all these difficulties and struggles, the proponent produces the GADIMATH's main features: user-friendliness, infotainment, authenticity, interactivity, learning support, portability, and changing environment. GADIMATH has seven functions: choose avatar, gameplay, backpack, shop, settings, help, and about that are merged to form a final and impeccable product.

Methods. An accelerated application improvement model was used in the study because the development of GADIMATH was divided into small modules and compounded to produce a final product. This model was employed since the progress and development of the project were surveyed through several stages. These stages are the requirements planning, user description, construction, and cutover. The instrument includes 24 measures. However, only twelve measures were considered relevant to product features. Twenty-five respondents were selected to test the application, whereas 10 are teachers and 15 fifteen students. After the data were gathered, the proponent used frequency distribution to determine if the game's purpose has been achieved. Then the average results were generated and compute the percentile rank and its mean scores.

Results. The game is being described as an excellent game since all of the attributes are "Excellent". These attributes were matched along with the product features and their mean scores. The userfriendliness is composed of three software quality attributes and its scores: Operability 4.79, Training 5.00, and Communicativeness 4.84. These results in the mean score of 4.88; Infotainment comprises two software quality attributes and its scores: Completeness 4.72 and Consistency 4.85 . These results in the mean score of 4.79 ; the Reliability feature comprises three software quality attributes and its scores, namely Accuracy 4.68, Simplicity 4.92, and Consistency 4.85. These results in the mean score of 4.82; Interactivity is composed of two software quality attributes and its scores, namely: Simplicity 4.92 and Communicativeness 4.84 . These results in a mean score of 4.88 ; the Learning Reinforcement feature comprises three software quality attributes and its scores: Consistency 4.85 , Conciseness 4.60, and Modularity 5.00. These results in the mean score of 4.82; Portability comprises three software quality attributes and its scores, namely: Hardware Independence 5.00, Modularity 5.00, and Completeness 4.72. These results in a mean score of 4.91. Lastly, the Dynamic Environment feature comprises three software quality attributes and its scores: Generality 4.79, Expandability 4.84, and Modularity 5.00. These attributes resulted in a mean score of 4.88 . These attributes show that the game provides a clear, concise, accurate, and complete output.

Conclusion. The development of GADIMATH to school institutions helps students supplement their knowledge in learning discrete mathematics in gamification. Also, it provides a supplementary education tool for teachers who are handling discrete mathematics. The game development helps students improve their mind-setting purposes as they respond to all the problems for each level 
of the game while appreciating the whole experience. As GADIMATH observes the scaffolding of exercises based on the curriculum given by the Commission on Higher Education (CHED), it considerably assists students in learning the topic because the game itself matches the sequence of the topics given the CHED. The implementation of the game's features and functionalities makes it useful and usable to school institutions who are offering discrete mathematics and to the students who are currently taking or have finished the said course.

Practical Value of the Paper: Implementing a gamified application in teaching helps educators find the balance between achieving their objectives and catering to evolving student needs. Using gamified applications can greatly help students learn by doing, which ultimately improves their processes and outcomes.

\section{References}

Brull, S., \& Finlayson, S. (2016). Importance of gamification in increasing learning. The Journal of Continuing Education in Nursing, 47(8), 372-375. DOI: 10.3928/00220124-20160715-09. Dichev, C., \& Dicheva, D. (2017). Gamifying education: what is known, what is believed and what remains uncertain: a critical review. International journal of educational technology in higher education, 14(1), 9. DOI: 10.1186/s41239-017-0042-5.

Elshiekh, R., \& Butgerit, L. (2017). Using gamification to teach students programming concepts. Open Access Library Journal, 4(8), 1-7. DOI: 10.4236/oalib.1103803.

Fortes Tondello, G., Premsukh, H., \& Nacke, L. (2018, January). A theory of gamification principles through goalsetting theory. Hawaii International Conference on System Sciences. Retrieved from http://hdl.handle. net/10125/50027.

Ganal, N. N., \& Guiab, M. R. (2014). Problems and difficulties encountered by students towards mastering learning competencies in mathematics. Researchers World, 5(4), 25. Retrieved from https://tinyurl.com/yyhwh2jg.

Hsu, S. H., Chang, J. W., \& Lee, C. C. (2013). Designing attractive gamification features for collaborative storytelling websites. Cyberpsychology, Behavior, and Social Networking, 16(6), 428-435. DOI:10.1089/cyber.2012.0492.

Kasurinen, J., \& Knutas, A. (2018). Publication trends in gamification: A systematic mapping study. Computer Science Review, 27, 33-44. DOI: 10.1016/j.cosrev.2017.10.003.

Khalid, N., Zainuddin, N. Z., \& Nuwairi, N. Meaningful Gamification: A Conceptual Model of Discrete Math in a Flipped Classroom. Retrieved from https://tinyurl.com/y2dv9wwh.

McLoughlin, J., \& Sabir, T. (Eds.). (2017). High-Performance Apparel: Materials, Development, and Applications. Woodhead Publishing. DOI: 10.1016/B978-0-08-100904-8.09993-4.

Paterson, J., \& Sneddon, J. (2011). Conversations about curriculum change: Mathematical thinking and team-based learning in a discrete mathematics course. International Journal of Mathematical Education in Science and Technology, 42(7), 879-889. DOI: 10.1080/0020739X.2011.613487.

\section{Correspondence:}

Jan Mark S. Garcia [markjj06.garcia@gmail.com]

https://orcid.org/0000-0002-3306-0507 